\title{
A Field Comparison of Distance and Plot Methods for Regeneration Surveys
}

\author{
by
}

\author{
D. A. MacLeod and M. A. Chaudhry'
}

\begin{abstract}
A survey method involving the measurement of the distance from a sample point to the nearest seedling was compared with the usual stocked plot approach for estimating percent stocking to 1-milacre $\left(4 \mathrm{~m}^{2}\right)$ plots $^{2}$. Ten separate surveys were run for each method over a 100-acre (40 ha) test area, and the results compared with respect to stocking accuracy and practical utility. The distance approach was found to be more efficient, requiring on the average substantially fewer samples to achieve the same level of accuracy. Time requirements per sample were slightly greater than for the stocked plot approach and the equipment was more cumbersome.

The theoretical basis for estimating stocking from a distance survey is described, and an estimation procedure is presented.
\end{abstract}

\section{Résumé}

On compare une méthode d'inventaire utilisant le mesurage de la distance d'un point d'échantillon au semis le plus proche avec la méthode courante de la placette pourvue pour évaluer en pourcentage le matériel relatif de placettes d'un milli-acre $\left(4 \mathrm{~m}^{2}\right)$. On a exécuté dix inventaires différents pour chaque méthode sur un terrain-test de 100 acres pour ensuite en évaluer les résultats tant qu'à la présence exacte de matériel relatif et le côté pratique. On a trouvé que la méthode par distance était plus efficace, requérait en moyenne moins d'échantillonnage pour obtenir le même degré d'exactitude. Le temps pour mesurer un échantillon était un peu plus long que pour l'approche par placette pourvue et l'outillage un peu plus encombrant.

Le principe qui sert en théorie à évaluer le matériel relatif par inventaire à distance y est décrit ainsi qu'une technique pour faire l'évaluation.

\section{Introduction}

Survey methods which involve the measurement of the distance from a sample point to a plant, or from one plant to another, are commonly used to study distributions in plant populations. These distance methods are considered to be particularly suited for determining the degree of clustering or spatial aggregation of a population (Clark and Evans 1954, Pielou 1959, Cox 1970). They have been applied as well to the estimation of population densities, though with less success (Morisita 1954, Catana 1963, Persson 1971). Their use in estimation of forest stand volumes is well established (Prodan 1968 and others).

The impact of distance methods on the study of forest regeneration has been very limited. They have not appeared to be directly applicable to the estimation of stocking levels, which is the goal of most regeneration surveys.

In forest regeneration measurement, stocking refers to the percentage of sample plots of a fixed size - normally 1 milacre $\left(4 \mathrm{~m}^{2}\right)$ - that contain at least one seedling (Figure 1). When calculated for a set of sample plots distributed over a regeneration area, it provides an estimate of the proportion of the area that is occupied by seedlings. Stocking is generally considered to be of more value than number of stems per unit area in assessing the adequacy of regeneration.

${ }^{1}$ D. A. MacLeod is a statistician with the Petawawa National Forestry Institute, Canadian Forestry Service, Department of the Environment, Ottawa, Ontario.

M. A. Chaudhry is an assessment specialist with the Advisory Services Section, Fores Resources Branch, Division of Forests, Ontario Ministry of Natural Resources, Toronto. Ontario.

21 milacre $=.001$ acres $=4.04686 \mathrm{~m}^{2}$.
It is in fact possible to estimate percent stocking by distance methods (Figure 2). This is a result of the close relationship between stocked-plot sampling, using circular plots, and the sampling of the distance from a point to the nearest seedling. This relationship is described in detail later in this paper. It does not appear to be widely known, as very few studies have attempted a direct comparison between distance and plot methods for estimating stocking. Also, there has not been much interest in such a comparison, since plot surveys are simpler and more direct, and have been assumed to be more efficient.

This paper presents the results of an attempt to compare distance and plot methods directly, with respect to both their accuracy of estimating percent stocking for 1-milacre $\left(4 \mathrm{~m}^{2}\right)$ plots and their practical utility. The project was carried out on a 100 acre (40 ha) test site and was run in two separate phases.

The 'establishment' phase involved a relatively intensive systematic survey using both plot and distance methods, conducted with considerable care to establish a reliable stocking value against which meaningful comparisons could be made. In the second or 'operational' phase twenty further surveys were run over the same area, ten for plots alone and ten for distances alone. These latter surveys were done fairly rapidly with only as much care as would be taken in an operational regeneration cruise. Comparison of the operational stocking results with the established stocking value provided estimates of bias and standard error for both methods. The point-centred quarter design was employed for the distance sampling in both phases (Figure 2).

\section{Selection and Description of the Test Area}

The criteria used to select the test area were that it be: 1. a cutover area about 5 to 10 years old, regenerating naturally or by direct seeding,

2. typical of the boreal forest region of Ontario with respect to species and topography, and

3. marginal between success and failure - i.e. around $50 \%$ of stocking.

The test site consisted of gently rolling hills having some
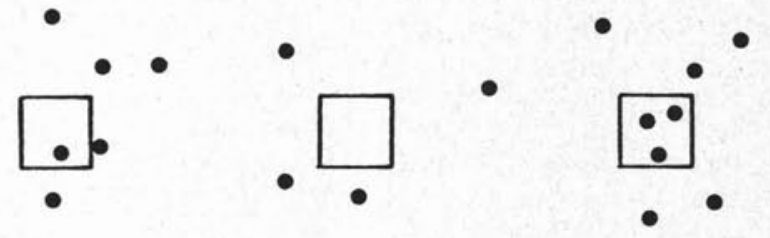

\section{- Seedling}

Fig. 1. Sampling with stocked plots or 'quadrats'.

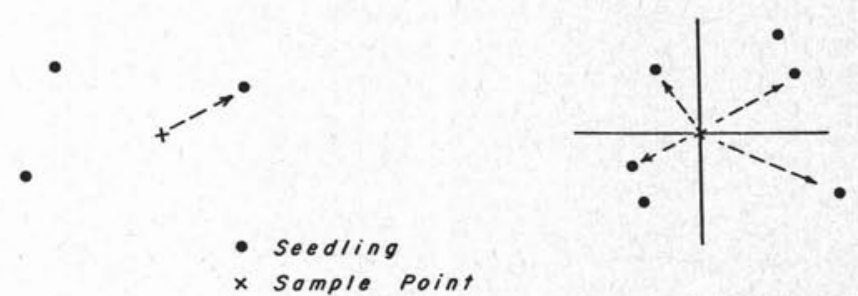

Fig. 2. Sampling the distance to the nearest seedling. 
rock outcrops and scattered wet depressions. The soil was a glacial till supporting mixed stands of poplar (Populus tremuloides Michx.), jack pine (Pinus banksiana Lamb.) and spruce (Picea glauca (Moench) Voss and Picea mariana (Mill.) B.S.P.) with a component of balsam fir (Abies balsamea (L.) Mill.) and white birch (Betula papyrifera Marsh.). The area was logged during 1969, leaving a heavy residual of low grade poplar and white birch with considerable logging debris. It was scarified with sharkfin barrels in 1971, levelling all residual trees and exposing about 20 percent mineral soil, then aerially seeded to jack pine in 1972. This seeding resulted in insufficient stocking due to heavy competition and unsuitable site conditions. The area was later site prepared and seeded with a Bracke Cultivator in 1974. The resulting stand had a marginal jack pine stocking and closely resembled a typical boreal mixedwood stand of natural origin.

\section{Survey Design and Sampling Procedure}

\section{Establishment Phase}

A rectangular area 36 chains by 28 chains $(728 m \times 563 m)$ was delineated on the selected site and a square grid sample design was set out across it (Figure 3). A total of 252 locations was marked at 2-chain $(40 \mathrm{~m})$ intervals along transverse sample lines, the lines being 2 chains apart. At each location point a cluster of 4 square, 1-milacre plots was located and the stocking recorded (Figure 4). The distances from the point to the nearest coniferous seedling and to the nearest seedling of any species were taken in each quarter. A limit of $10 \mathrm{ft}(3,05 \mathrm{~m})$ was imposed on the distance searched for seedlings. The maximum area searched for any seedling was 1.82 milacres $\left(7.31 \mathrm{~m}^{2}\right)$, which was considered to be sufficient for the purpose of this study.

This clustered design was employed because of the substantially lower sampling time per plot or per distance compared to a design of single plots. A study of simulated seedling populations (MacLeod 1977) suggested that this represented a reasonable compromise between accuracy and sampling time required.

This phase was performed carefully with locations determined by chaining along previously marked lines. The boundaries $X A, X B, X C$ and $X D$ were delineated by ropes stretched between stakes. A crew of four carried out this phase, which took up roughly half of the total time spent in the field.

\section{Operational Phase}

Following the establishment survey, 20 operational surveys were run over the test area - 10 sampling stocked plots and 10 taking distances only. Each survey consisted of 50 clusters with 4 plots or distances per cluster. The same layout was used as in Figure 4, with the same 120 in (3.05 m) limit on the distances. The clusters were set out along 5 (roughly) equidistant lines, with 10 clusters evenly spaced along each line (Figure 5). The starting distances $a$ and $b$ were selected at random with different values for different surveys.

The sampling techniques for this phase were much less stringent. Two 2-man crews were employed, each crew doing 5 plot and 5 distance surveys. The transverse lines were run along hand-held compass bearings and the distances between locations were paced rather than measured. Plot boundaries and boundaries between quarters were gauged by eye rather than measured, and the search for seedlings in each plot or quarter was less thorough than in the establishment phase.

The surveys were paired to sharpen the plot-distance comparison. Pairs consisting of one plot and one distance survey were assigned the same random starting distances and were performed by the same crew.

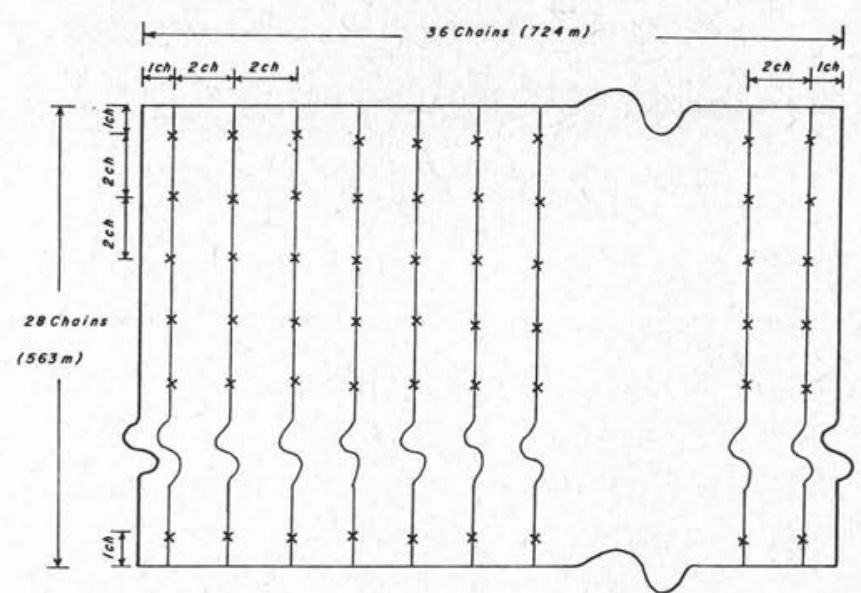

Fig. 3. Location of clusters for the establishment survey. The crosses indicate the centre of the clusters, whose layout is given in Figure 4.

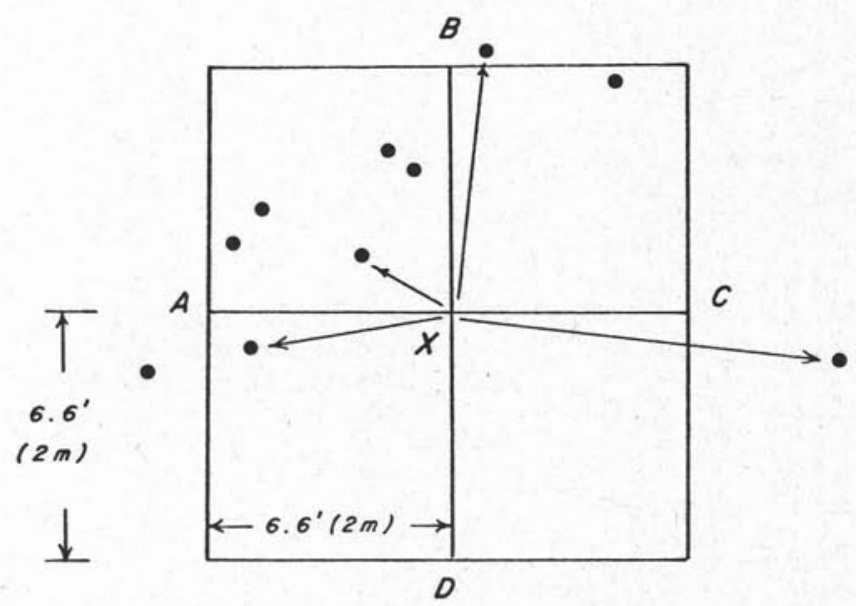

Fig. 4. Layout of a cluster of 4 plots and 4 distances in the estab. lishment survey.

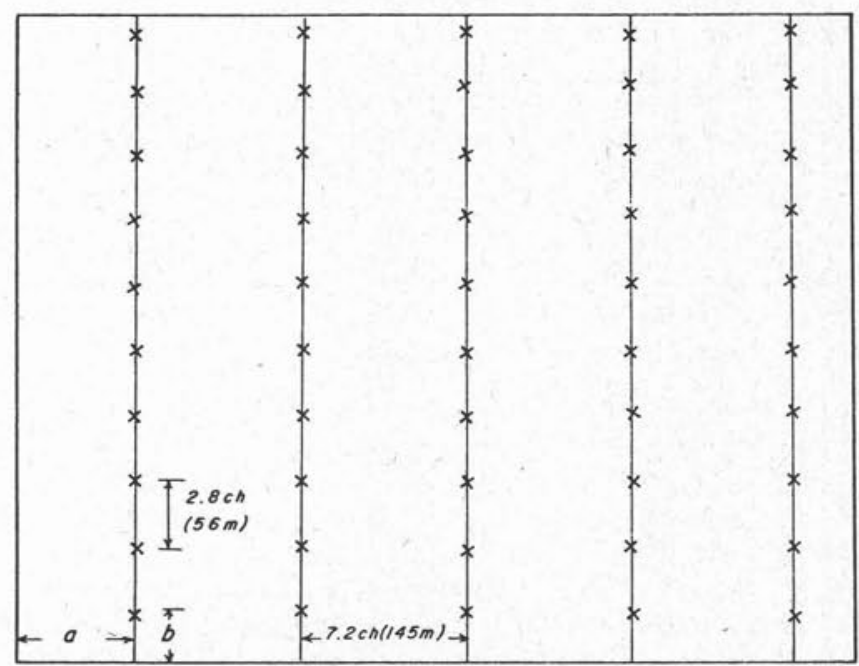

Fig. 5. Typical layout of clusters for an operational survey.

\section{Derivation of Stocking Estimates from Distance Samples}

The concept of stocking is not restricted to plots of milacre size, although that is the size generally employed. Stocking can be calculated for plots of any size, the larger the size the higher the stocking level for any given regeneration area. Plots are usually square, though other shapes can 


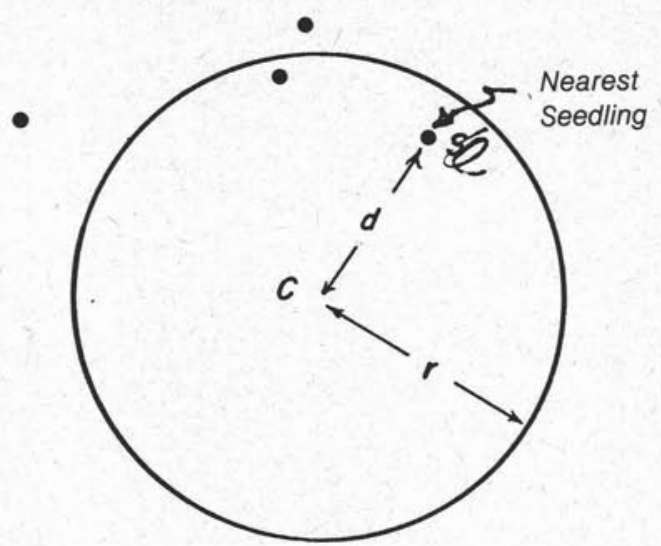

Fig. 6. Stocking-distance relationship for circular plots.

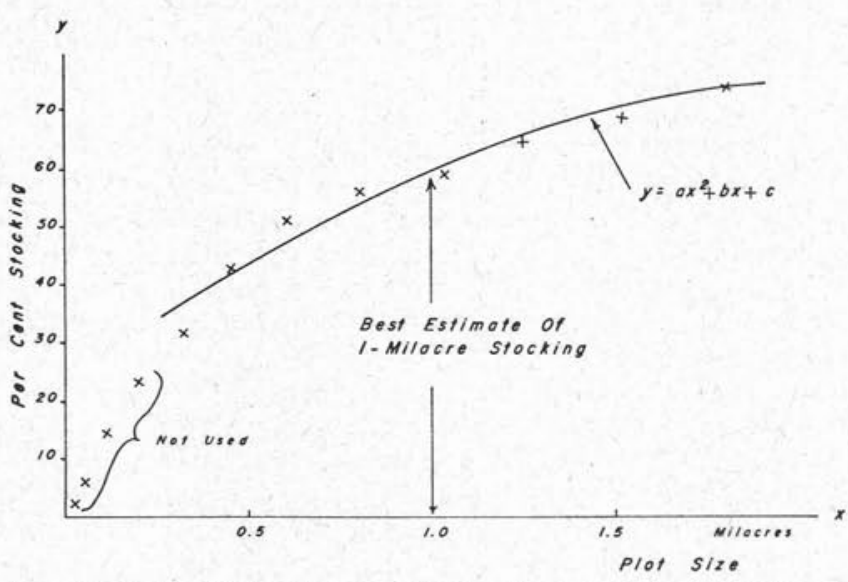

Fig. 7. Graph of stocking vs plot size for one of the operational surveys

be used. In general, stocking is affected only by plot size, not by shape.

Distance sampling is closely related to stocked plot sampling with circular plots. Consider a circular plot of radius $r$ centred at a point $C$ (Figure 6), with $d$ being the distance to the nearest seedling $S$. If $d$ is less than $r, S$ is within the plot; conversely, if $d$ is greater than $r$ then $S$ and all the other seedlings are outside the plot. Therefore the plot is stocked or unstocked depending on whether $d$ is less than $r$ or greater than $r$.

It follows that if (d) is the set of sample distances from a survey, the percentage of the $d$ that are less than any fixed value $r_{0}$ provide a direct estimate of percent stocking or circular plots of radius $r_{0}$. The same relationship holds between the distance to the nearest seedling within each quarter and stocking to plots of quarter-circle shape.

Stocking estimates for milacre plots could have been obtained in this fashion from the results of the distance surveys in this project. These estimates would not have reflected any theoretical advantage over the stocked-plot survey estimates, however, since the only difference would have been, in effect, the use of quarter-circle plots instead of square ones.

The procedure followed in this study is a refinement of the above method. It makes use of the fact that it is possible to calculate the percentage of distances less than $r$ for any value of $r$ up to the maximum limit $-10 \mathrm{ft}(3.05 \mathrm{~m})$ in this study - so that a single distance survey thus provides direct stocking estimates for a range of (circular) plot sizes. This procedure enables the distance method to make use of more information and thus, theoretically, to give more accurate results than the stocked-plot method.

Twelve different radius values were selected: 10 in, 20 in,
30 in, .., 120 in $(25 \mathrm{~cm}, 50 \mathrm{~cm}, \ldots, 305 \mathrm{~cm})$. For each operational survey, the percentage of the distances that were less than each radius value were tabulated. This provided, for each survey, a stocking estimate for each of 12 sizes of circular plot. These estimates can be expressed as data points in the graph of stocking vs. plot size (Figure 7).

The next step was to utilize these estimates to derive, for each survey, the best estimate of stocking for 1-milacre plots. Since stocking must in theory increase smoothly as plot size increases, the problem is basically to fit a curve of stocking vs. plot size through each set of data points (Figure 7 ), and obtain the 1-milacre stocking value from each fitted curve.

An examination of the graphs suggested that standard curve fitting techniques should be adequate for this purpose. A quadratic curve

$$
y=a x^{2}+b x+c
$$

was fitted to each data set using standard linear regression techniques, where $x$ is plot size, $y$ is stocking level and $a, b$ and $c$ are constants estimated for each curve. Each curve was fitted through only the 8 data points corresponding to circular plots of radius 50 in to 120 in $(127 \mathrm{~cm}$ to $305 \mathrm{~cm}$ ). The other 4 points were not used, as they were outside the range of interest. The graphs of stocking vs plot size appeared to curve more sharply over the lower range of plot size, so that the inclusion of those data points might distort the fitted curve and bias the estimates of stocking for 1 -milacre plots.

In fitting the curves, care was taken to employ methods that were as universal as possible and could be applied to any regeneration situation. The quadratic curve was chosen because it provided an adequate fit over the plot size range of interest, and involved no assumption regarding the nature of the seedling distribution (other than that the graph is a smooth curve).

It should be noted that the ordinates of the data points of any survey are serially correlated, though this does not invalidate the resulting stocking estimate. The correlation would increase if the intervals between data points were smaller, and could reduce the potential benefit from having more data points.

\section{Calculation of the Results}

A stocking estimate $S_{i}$ was obtained for each of the 10 operational distance surveys, as outlined in the previous section. Estimates were also taken directly from the 10 plot surveys. These results were obtained for both the coniferous seedling population and for the population of all species $^{3}$, as shown in Table 1. The 'within' standard error of the $S$ was calculated from the deviations from their mean $\bar{S}$, while the 'total' standard error is that of the deviation from $S$. The later error includes a component $\left(\overline{\mathrm{S}}-\mathrm{S}_{t}\right)^{2}$ for the bias of the $S_{i}$. This bias component will be affected by the fact that $S_{\text {i }}$ is an estimate, not exactly equal to the true stocking level. However, $S_{i}$ is considered to be sufficiently accurate to be used as the true stocking level in this study.

\section{Discussion of Results}

\section{Sampling Accuracy}

The biases were small for both plot and distance methods, with neither showing any pattern of either overestimation or underestimation of stocking levels.

There were considerable differences among the standard error results. The plot method was, on the average, less accurate than the distance method, as expected from

${ }^{3}$ Saplings were ignored if their Dbh was greater than 2.0 in $(5.08 \mathrm{~cm})$. Seedlings were ignored if their heights were below the following limits: spruce 4 in $(10 \mathrm{~cm})$. jack pine 6 in $(15 \mathrm{~cm})$, balsam fir 8 in $(20 \mathrm{~cm})$ white birch 30 in $(76 \mathrm{~cm})$, aspen 36 in $(91 \mathrm{~cm})$. 
Table 1. Percent stocking estimates and standard errors

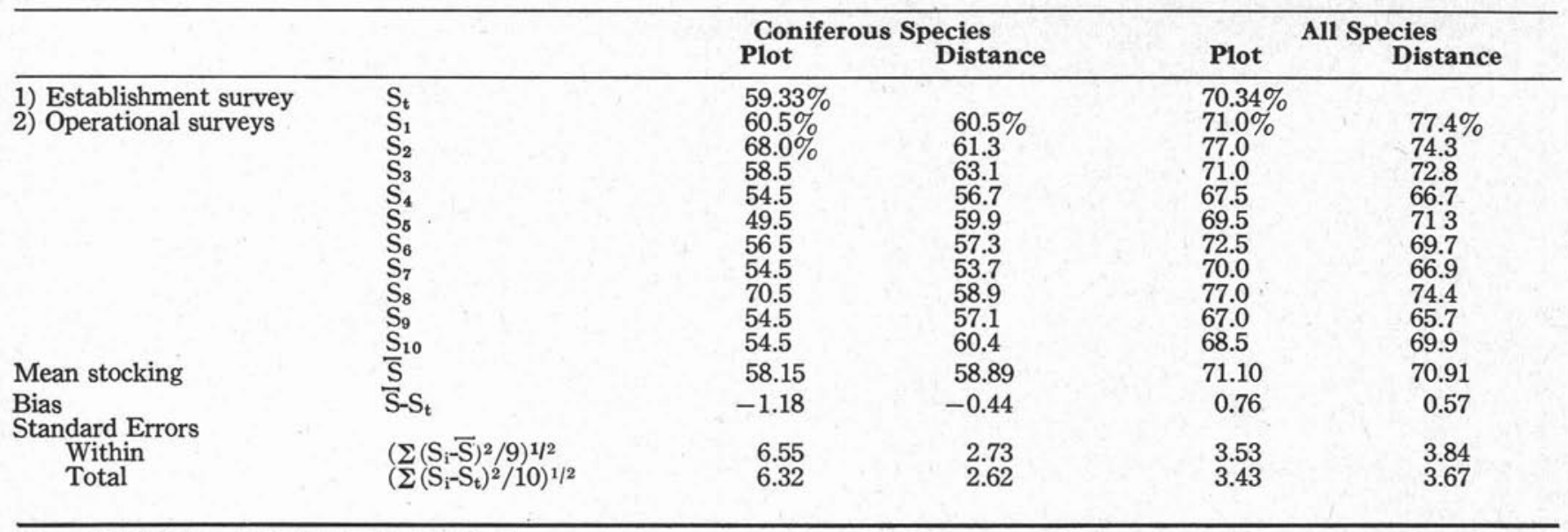

Note: $(\text { S.E. Total })^{2}=(9 / 10)(\text { S.E. Within })^{2}+$ Bias $^{2}$

theoretical considerations. There was some inconsistency between results for the two populations (conifers only, and all species combined). This was attributed partly to the small number of surveys run. In addition, the "all species" population was more strongly clustered than the coniferous population with more of the plots falling in either densely stocked areas or in areas devoid of seedlings. The sampling crew thus had to make more borderline decisions than with the coniferous population. Distance sampling avoids this borderline problem as there is no fixed plot size.

A pooling of the results for both populations gives:

$\begin{array}{lcc} & \begin{array}{c}\text { Plot } \\ \text { Surveys }\end{array} & \begin{array}{c}\text { Distance } \\ \text { Surveys }\end{array} \\ \text { "Total" standard error } & 5.08 \% & 3.19 \% \\ \text { "Within" standard error } & 5.26 \% & 3.33 \%\end{array}$

The errors for the distance surveys were significantly lower than for the plot surveys, at the $95 \%$ confidence level. In fact, the efficiency (the ratio of the squares of the standard errors) of the distance surveys was over twice that of the plot surveys; i.e. could achieve the same level of accuracy with only $40 \%$ to $45 \%$ as many samples.

\section{Practical Utility}

The distance surveys took somewhat longer to complete. The average sampling times per cluster of 4 plots or distances, excluding travel times between clusters, were:

\section{Distance Surveys}

\section{5 minutes}

Plot Surveys

2.0 minutes

This extra time was attributed to the fact that each distance had to be measured, while with plot sampling the stocking could often be judged by eye. Distance sampling thus placed greater demands on the field crew. In some instances several seedlings had to be checked to find the nearest one. For our project, distance sampling took up roughly $10 \%$ more total field time than plot sampling.

Other factors also affected the sampling time comparison. The difference was greater if stocking was estimated separately for several different species, as each species then required its own distance measurement. On the other hand, distance methods were relatively faster on heavily overgrown sites where the setting out of plot boundaries was difficult.
Another disadvantage was that the equipment employed in the distance surveys - a wooden cross $2 \mathrm{ft}(60 \mathrm{~cm})$ in width nailed onto a stake to be set down at the group centre, and a $10 \mathrm{ft}(3 \mathrm{~m})$ measuring stick or tape - were more cumbersome than the graduated rope and $6.6 \mathrm{ft}(2 \mathrm{~m})$ pole used in the plot surveys. They were also more subject to loss or damage and more difficult to replace.

It should be possible to reduce these disadvantages by improving the methodology for distance surveys. The measurement of each distance to the nearest inch turned out to be unnecessary in this study, for example. A simplified procedure, that would still have been sufficient for the calculations presented in this paper, would be to classify distances rather than measuring them. Distances could be assigned to one of the following classes: Less than 50 in $(127 \mathrm{~cm}), 50$ in to 60 in $(127 \mathrm{~cm}$ to $152 \mathrm{~cm}), 60$ in to 70 in $(152 \mathrm{~cm}$ to $178 \mathrm{~cm}), \ldots 110$ in to 120 in $(279 \mathrm{~cm}$ to $305 \mathrm{~cm})$, or greater than 120 in. Experienced field personnel might be able to classify many distances without actual measurement.

The equipment might also be improved. The field crew suggested a graduated rope attached to the centre cross would be simpler than a measuring stick or tape for taking distances. The cross could be made stronger and lighter, perhaps of aluminum.

\section{Conclusion}

For the small number of surveys run in this study, distance methods provided more accurate and more consistent percent stocking estimates than the standard stocked plot or "quadrat" approach using milacre $\left(4 \mathrm{~m}^{2}\right)$ plots. A substantial gain in sampling efficiency (i.e. reduction in sample size for a given level of accuracy) may be possible through the use of distance methods, though extensive further work will be required before definite conclusions can be drawn.

Distance methods provided stocking estimates for any plot size within the range of .32 milacre to 1.82 milacres (1.3 $\mathrm{m}^{2}$ to $9.3 \mathrm{~m}^{2}$ ). This flexibility would enable comparisons to be made with fixed plot surveys using various sizes of plots.

The gain in accuracy was offset to some extent by a slightly greater time requirement per sample, compared to stocked plot surveys, and by more cumbersome equipment. The difference would depend on the terrain and vegetation cover and on the proportion of the total field time actually taken up by sampling. It may be possible to reduce these disadvantages by simplifying the sampling procedures and improving the equipment. 
References

Catana, J. A. 1963. The wandering quadrat method of estimating population density. Ecology 44:349-360.

Clark, P. J. and F. G. Evans. 1954. Distance to nearest neighbour as a measure of spatial relationships in populations. Ecology 35:445-453.

Cox, F. 1970. Are there any consistent parameters for distance methods if the spatial distribution deviates markedly from a bidimensional Poisson-process? IUFRO Conf. Advis. Group For. Statist., Section 25, Jouy-en-Josas, France, Inst. Nat. Rech. Agr., Publ. 1972-73; p. 247-259.
MacLeod, D. 1977. Accuracy of regeneration stocking estimates: tests with simulated data. For. Chron. 53:77-81.

Morisita, M. 1954. Estimation of population density by spacing method. Mem. Fac. Sci., Kyushu Univ., El:187-197.

Persson, O. 1973. On forestry regeneration surveys. Statistics in Forestry Research, IUFRO 4th Conf. Advis. Group For. Statist., Vancouver, Canada. August 1973. p. 17-35.

Pielou, E. C. 1959. The use of point to plant distances in the study of the pattern of plant populations, J. Ecol. 47:607-613.

Prodan, M. 1964. Forest biometrics. (Translated from German by S. H. Gardiner). Pergamon Press.

\begin{tabular}{|c|c|} 
CONSULTING & $\begin{array}{c}\text { Industrial Forestry } \\
\text { Service Ltd. } \\
\text { ENGINEERS }\end{array}$ \\
$\begin{array}{c}\text { Centrally Located for } \\
\text { Festern Canada's } \\
\text { Forest Industry } \\
\text { 101 - 1595 FIFTH AVE. } \\
\text { PINCE GEORGE, B.c. } \\
\text { TEL.: (604) 564-4115 }\end{array}$ \\
\hline
\end{tabular}

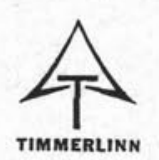

Tel.: (819) 326-3559

\section{TIMMERLINN UMrete LIMITED}

PROFESSIONAL AND TECHNICAL SERVICES IN FORESTRY AND ENVIRONMENTAL SCIENCES

R.R. No. 2, STE. AGATHE DES MONTS, QUE. J8C $2 Z 8$

\section{ETES-VOUS CERTAIN QUE VOTRE PROGRAMME D'ASSURANCE-VIE RÉPOND AUX BESOINS DE CEUX QUI COMPTENT SUR VOUS?}

Grâce à votre régime d'assurance IFC, il vous est possible d'obtenir une protection à des taux exceptionnellement bas.

Pour plus de détails, veuillez écrire à l'Institut Forestier du Canada, Collège Macdonald, B.P. 5000, Québec H9X 1 CO.

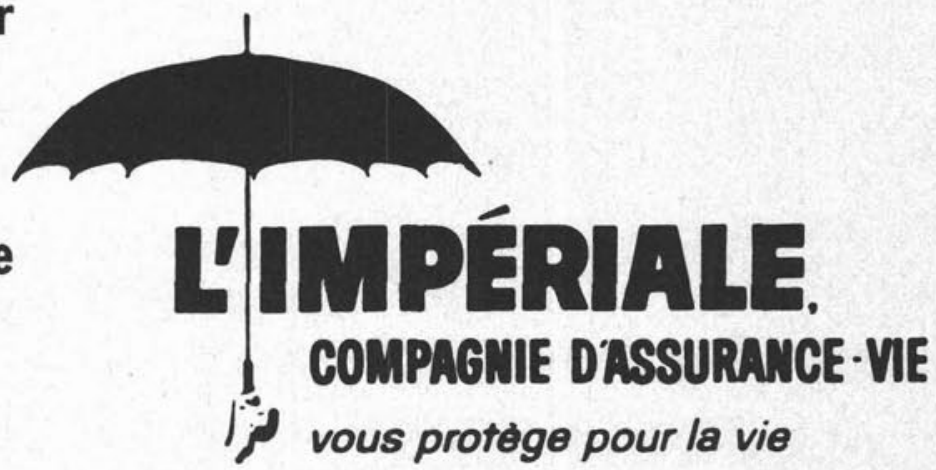

